\title{
Temporary sequential atrioventricular pacing in myocardial infarction
}

\author{
N. Sheron and M. Clarke \\ City General Hospital, Stoke on Trent ST4 6QG, UK.
}

\begin{abstract}
Summary: The loss of atrial contraction can seriously impair cardiac output when complete heart block follows myocardial infarction. We describe two cases in which temporary sequential atrioventricular pacing was lifesaving. The pacemaker used was a previously explanted internal pacemaker. By avoiding the need for an expensive dedicated temporary pacemaker this technique may be more widely applied.
\end{abstract}

\section{Introduction}

Complete heart block is a common complication of myocardial infarction, often associated with cardiogenic shock. We describe two patients in whom restoration of atrial transport led to immediate clinical improvement using techniques which could be applied in the coronary care units of any district general hospital.

\section{Case reports}

Case 1

A 63 year old man presented with an inferior myocardial infarction. He was poorly perfused with sinus bradycardia which improved with atropine and dobutamine. An episode of ventricular tachycardia required DC shock and lignocaine. Subsequently he developed complete heart block with a ventricular rate of 40-50 which required insertion of a temporary right ventricular pacing electrode. Over the next 16 hours he remained unwell with generalized vasoconstriction and a low urine output.

An atrial pacing electrode was inserted via a second subclavian venepuncture alongside the ventricular lead. Sequential atrioventricular pacing was established with $P$ wave tracking occurring at rates above 70 beats/minute. His clinical condition improved rapidly as regards blood pressure and peripheral perfusion, allowing the dobutamine to be discontinued.

His improvement was maintained and he developed sinus rhythm at 7 days. The pacing electrodes were

Correspondence: N. Sheron, M.B., Ch.B.

Accepted: 22 August 1986 removed and he was discharged from hospital 14 days post-infarction. $\mathrm{He}$ is asymptomatic 5 months later.

\section{Case 2}

A 58 year old man presented with an anterior myocardial infarction in complete heart block with asystolic episodes. Temporary pacing was attempted. As the lead would neither sense nor pace at the right ventricular apex it was positioned in the right ventricular outlet, away from infarcted muscle. For the following 48 hours he remained unwell. He was poorly perfused and in left ventricular failure with systolic pressures of 80 to $100 \mathrm{~mm} \mathrm{Hg}$ on maximum doses of inotropic support. An atrial pacing lead was therefore inserted and sequential atrioventricular pacing commenced with tracking of the native $P$ waves. Again, immediate haemodynamic improvement was noted enabling dobutamine to be discontinued after 24 hours. One episode of atrial flutter occurred and was terminated by atrial burst overdrive packing. On the fifth day he developed a traumatic ventricular septal defect. Cardiac catheterization demonstrated occlusions of the anterior descending and distal right coronary arteries. Open heart surgery was performed to repair the defect and graft the coronary arteries. He was discharged from hospital in sinus rhythm after 3 weeks and remains well 4 months later.

\section{The technique}

A cordis $5 F$ 370-410 temporary atrial bipolar pacing lead was introduced alongside the ventricular lead under X-ray screening by junior medical staff without difficulty.

(C) The Fellowship of Postgraduate Medicine, 1987 
The Biotronik Diplos 05 DDD pacemaker had been previously explanted and was therefore unsuitable for reimplantation. For convenience it had been placed in a small plastic box and programmed at appropriate sensitivities and outputs commensurate with sensing and threshold measurements of the leads (ventricular/ atrial pulse width $1 \mathrm{~ms}$ at $5 \mathrm{~V}$ both channels, sensitivity; atrial $1 \mathrm{mV}$, ventricular $2.5 \mathrm{mV}$, delay $150 \mathrm{~ms}$ ).

\section{Discussion}

Atrial transport provides up to $30 \%$ of cardiac output. ${ }^{1,2,3}$ AV sequential pacing produces substantial haemodynamic benefit in patients with heart block complicating myocardial infarction. ${ }^{4}$ Restoration of atrial transport function is most dramatically effective

\section{References}

1. Fowler, M.B., Crick, J.C.P., Taylor, D.I. et al. Single lead atrial synchronised pacing in patients with cardiogenic shock after acute myocardial infarction. Br Heart J 1984, 51: 622-625.

2. Leinbach, R.C., Chamberlain, D.A., Kastor, J.A., Harthorne, J.W. \& Sanders, C.A. A comparison of the hemodynamic effects of ventricular and sequential AV pacing in patients with heart block. Am Heart $J$ 1969, 78: $502-508$.

3. Chamberlain, D.A., Leinbach, R.C., Vassaux, C.E., Kastor, J.A., DeSanctis, R.W. \& Sanders, C.A. Sequential in those with extensive myocardial damage; this benefit was immediately apparent in both our patients. $\stackrel{\mathbb{Q}}{\Omega}$ The requirement for inserting a second pacing lead has $c$ restricted the widespread adoption of this technique. $\vec{F}$ However, our experiences demonstrated that $\stackrel{\text { ? }}{\rightarrow}$ placement of an atrial lead can be achieved by those familiar with standard pacing techniques. The use of a standard dual chambered pacemaker overcomes the $\frac{\rho}{\sigma}$ necessity of having a specific complex temporary pacing system. ${ }^{5}$

Though readjustment of pacing and sensing thresholds would require the use of a pacemaker programmer this was not found to be a practical disadvantage. $\vec{\omega}$ AV sequential pacing was lifesaving in our two patients, using equipment and techniques whicho deserve wider application.

atrioventricular pacing in heart block complicating acute $\stackrel{\circ}{\triangle}$ myocardial infarction. $N$ Eng J Med 1970, 282: 577-582. 4. Samet, P., Castillo, C. \& Berstein, W.H. Hemodynamic ${ }_{\overparen{D}}^{\top}$ sequelae of atrial, ventricular and sequential atrioven-D tricular pacing in cardiac patients. Am Heart J 1966, 294: 725-729.

5. Valentini, R., Greco, E.M., Sernesi, L., Arlotti, M. \& L\&to, A. Temporary pacing in A.M.I. complicated by $\infty_{\infty}$ block: Haemodynamic changes during VVI, DVI, VDEI ${ }^{-}$ pacing with external Sorin PMMP 80 Pacer. Pace 1983, A129. 